\title{
Before my time? Addressing the intergenerational legacies of the genocide against the Tutsi in Rwanda
}

\author{
Veroni Eichelsheim ${ }^{1}$, Lidewyde Berckmoes ${ }^{1}$, Barbora Hola ${ }^{1,2}$, Theoneste Rutayisire ${ }^{3}$ \& Annemiek Richters ${ }^{4}$ \\ ${ }^{1} \mathrm{PhD}$ : Senior Researcher at Netherlands Institute for the Study of Crime and Law Enforcement (NSCR), ${ }^{2}$ Associate Professor at the Faculty of Law, Vrije \\ Universiteit (VU), ${ }^{3} \mathrm{PhD}$ : Researcher at Amsterdam Institute for Social Science Research (AISSR), Amsterdam, The Netherlands, ${ }^{4} \mathrm{PhD}$ : Emeritus Professor at \\ Amsterdam Institute for Social Science Research (AISSR), Amsterdam, The Netherlands
}

\section{Abstract}

This study aims to (i) understand how the legacies of the 1994 genocide against the Tutsi and its aftermath are transmitted to the next generation within Rwandan families and (ii) explore how institutional support plays a role in the pathways of intergenerational transmission. Through an in-depth analysis of qualitative interviews with 41 mothers and one of their adolescent children, we identified direct and indirect pathways through which the legacies of the genocide are transmitted to the second generation. Direct pathways concern the ways in which the genocide and its aftermath are reflected upon, reconstructed and explicitly communicated or silenced to the second generation. Indirect pathways are ways in which the genocide and its aftermath affect the life circumstances of the children, and through that, the child. Many of the included households had access to at least some kind of support. In general, our results indicate that organisations providing support to families and individuals in post-conflict settings might want to consider focusing explicitly on the identified pathways of intergenerational transmission to improve the living conditions of the next generation(s).

Keywords: Genocide, intergenerational transmission, Rwanda

\section{KEY IMPLICATIONS FOR PRACTICE}

- Development organisations that provide support to families in post-conflict settings could specifically address parenting, family relations and family communication and interactions to help participants secure a safe environment for the next generations to grow up in

- Development organisations in post-conflict settings could specifically facilitate and encourage the interactions of participants with the broader social environment and the community to stimulate cooperation and social support

- Stimulating the development of economic cooperation among the participants of support programmes in post-conflict settings as well as within their communities may be helpful in reducing intergenerational poverty.

\section{INTRODUCTION}

There is ample empirical evidence for the intergenerational transmission of violence, trauma and other mental health problems in post-conflict environments (e.g. Betancourt \& Williams, 2008; Betancourt, McBain, Newnham, \& Brennan, 2015; Roth, Neuner, \& Elbert, 2014; Saile, Ertl, Neuner, \& Catani, 2014; Weingarten, 2004). Research also shows that the intergenerational transmission of trauma and violence is affected by parenting behaviour, in which parenting behaviour may serve either as risk or protective factor (Berckmoes \& Reis, 2016; Gewirtz, Forgatch, \& Wieling, 2008). For instance, due to parents' traumatic experiences, parents may become less sensitive to children's needs or less available to their children, which can subsequently affect developmental outcomes, such as

\begin{tabular}{|l|l|}
\hline \multicolumn{2}{|c|}{ Access this article online } \\
\hline Quick Response Code: & $\begin{array}{l}\text { Website: } \\
\text { www.interventionjournal.org }\end{array}$ \\
& \\
& \\
\hline
\end{tabular}

children's well-being, educational achievements and social behaviour (Berckmoes \& Reis, 2016; Gewirtz et al., 2008; Roth et al., 2014). In addition, besides parental traumatic experiences there are indications that multiple other factors at family and societal levels shape the developmental outcomes of children growing up in post-conflict settings, including changes in family structure such as the loss of caregivers, poverty and other daily life struggles (Betancourt et al., 2015). Furthermore, there is evidence showing that

Address for correspondence: Dr. Veroni Eichelsheim, PhD: Senior Researcher at Netherlands Institute for the Study of Crime and Law Enforcement, Amsterdam, The Netherlands.

E-mail: veichelsheim@nscr.nl

This is an open access journal, and articles are distributed under the terms of the Creative Commons Attribution-NonCommercial-ShareAlike 4.0 License, which allows others to remix, tweak, and build upon the work non-commercially, as long as appropriate credit is given and the new creations are licensed under the identical terms.

For reprints contact: reprints@medknow.com

How to cite this article: Eichelsheim, V. I., Berckmoes, L., Hola, B., Rutayisire, T., \& Richters, A. (2019). Before my time? Addressing the intergenerational legacies of the genocide against the Tutsi in Rwanda. Intervention, 17(1), 31-39. 
Eichelsheim et al.: Intergenerational legacies of genocide

parental traumatic experiences, together with continuous family hardship, can be related to the increases of domestic violence such as intimate partner violence and harsh parenting (Rees, Thorpe, Tol, Fonseca, \& Silove, 2015). Research shows that growing up in violent environments may put children at a risk of future aggressive behaviour and mental health problems (Kim, 2009; Thornberry, Knight, \& Lovegrove, 2012). For children growing up in environments characterised by communal or societal violence (i.e. postconflict settings), research shows similar results (e.g. Rees et al., 2015; Saile et al., 2014).

In Rwanda, the 1994 genocide against the Tutsi and post1994-related events, such as the imprisonment of mainly male genocide suspects or convicts, led to large-scale individual and collective traumatisation, the disruption of family structures and shifts in gender roles. Furthermore, the aftermath of the genocide has been associated with the subsequent elevated rates of domestic violence (Rieder \& Elbert, 2013) and ongoing struggles among survivors, perpetrators and their family members to cohabit in communities (Buckley-Zistel, 2006). Among other psychosocial, medical or socio-economic initiatives, the community-based sociotherapy program (CBSP) has been implemented in Rwanda to address some of these challenges. CBSP aims to improve the psychosocial well-being of individuals and strengthen interpersonal reconciliation and social cohesion at the community level. It is designed as an alternative to individually focused (and thus expensive) trauma therapy (Dekker, 2016). It uses the group setting as a therapeutic medium for establishing trust, opening space for discussion and establishing peer-support structures (Box 1; Richters \& Sarabwe, 2014).

In this article we aim to, first, explore and understand the intergenerational transmission of legacies of the genocide in Rwandan families and, second, explore the role of sociotherapy - among the other forms of available sources of institutional support - on the processes of intergenerational transmission. The primary focus is on the pathways through which the legacies of the traumatic experiences of the genocide and its aftermath are passed on to the second generation within families in Rwanda. Special attention was given to the relation and interaction between mothers and their children.

\section{INTERGENERATIONAL TRANSMISSION IN RWANDA}

In Rwanda, the recurrent outbreaks of mass violence since 1959, as well as the 1994 genocide and its aftermath, led to drastic changes in family and societal structures. Of a total population of over 7 million, it is estimated that over 1 million people were killed (Rwanda, Ministry of Local Government, 2002). Roughly, 56\% of them were men (ibid). Many women survived as captives and were often subjected to extreme violence. Consequently, many of them nowadays continue to struggle with their physical, mental and social well-being (e.g. Neugebauer et al., 2009). Tens of thousands of individuals fled to neighbouring countries and/or were (often upon their return from exile) detained, tried and imprisoned on genocide-related charges by ordinary criminal and Gacaca community courts (Clark \& Kaufman, 2008). As a consequence of the killings and mass incarceration, the sex ratio and traditional gender roles in Rwandan society have been significantly modified (Rutayisire \& Richters, 2014). Women had to step into the void left by men and attend to roles traditionally occupied by men (Schindler, 2010). In addition, many women had to provide for their husbands who were and sometimes still are detained, often in poor conditions (Tertsakian, 2004). In addition, many families of convicted perpetrators were obliged to pay reparations to compensate for damages done by the convicts to goods and crops during the genocide. Furthermore, evidence seems to suggest that increased marital conflict and intimate partner violence can partly be attributed to genocide- and Gacaca-related factors (Rutayisire \& Richters, 2014; Sarabwe, Richters, \& Vysma, 2017; Umubyeyi, Mogren, Ntaganira, \& Krantz, 2014).

In this context, a concern exists over the intergenerational transmission of the legacies of the 1994 genocide from those who have experienced the genocide directly to those who may not have directly experienced it (i.e. the second generation represented by the children who were born just before, during or after 1994). However, there is a limited understanding of the mechanisms underlying the intergenerational transmission of the experiences of mass violence and its aftermath as well as of the ways to address this phenomenon through policy and practice. In this study, we use qualitative research to explore these issues. We investigate how the legacies of the genocide are being

\section{Box 1: Community-based sociotherapy in Rwanda}

Community-based sociotherapy (CBS) was initiated in Rwanda in 2005. To serve the massive psychosocial needs among the Rwandan population in the aftermath of the war and genocide in the best possible way, the clinic-based sociotherapy approach, as applied in psychiatric clinics in support of the treatment of traumatized refugees in the Netherlands, was adapted to the Rwandan post-genocide context and transformed in a community-based approach. CBS's objectives were to foster feelings of dignity, safety and trust among the Rwandan population, reduce mental and social distress and reduce disturbed and delayed development.

Sociotherapy in Rwanda is practised in sociotherapy groups (socio-groups) of an average of ten to fifteen people. The groups meet for approximately three hours a week, for a period of fifteen weeks. The meetings are held in a place that is located in the direct living environment of group participants, which they consider as safe. Two trained sociotherapists methodologically guide the groups through the sociotherapy phases of safety, trust, care, respect, new life orientations and memories. Throughout the journey, the following seven principles are applied: interest, equality, democracy, participation, responsibility, here-and-now and learning-by-doing. The sociotherapy phases and principles guide the group through a process of healing and social reconnection. The group members are facilitated to share ideas, take care of each other, address their current problems and support each other in processing painful memories. The journey participants go through provides them with a new understanding of the issues affecting their feelings, thoughts and behaviours, as well as enables them to think about the future again in constructive ways (see for more information: www.sociotherapy.org or Ingabire et al., 2017). 
Eichelsheim et al.: Intergenerational legacies of genocide

transferred from one generation to the next within families and what role community-based sociotherapy - among the other available sources of support - plays [Box 1] in (addressing) the intergenerational transmission.

\section{Methodological approach}

Our focus was on the processes of intergenerational transmission in the primary environment in which children grow up, namely the household or the family. We were particularly interested in the relationship and interactions between the mother and (one of) her child(ren), as representing the first and second generation, respectively.

\section{Sample}

The research included 41 households. We focused on mothers who experienced the genocide and one of their adolescent children who were - at the time of interviewing - still living in the household, and who were born shortly before, during or after the 1994 events. The participants in the study were sampled through the CBSP. We included a group of mothers who had already gone through the programme $(n=22)$, and a group of mothers who had not (yet) gone through it, but who were on the waiting list $(n=19)$.

In Table 1, more information is provided about the characteristics of these mothers. The mothers included in the current study were between 38 and 64 years old ( $M$ $=51.14$ ). Mothers with different social and economic backgrounds in different rural areas were included, thereby accounting for differences in socio-economic conditions and regional variation in genocidal violence, post-genocide justice and, consequently, variation in the potential legacies of the genocide and its aftermath. The research sites were geographically spread across Rwanda.

Table 2 provides more information about the 41 children interviewed in the current study. Among the interviewed children were more girls $(n=28)$ than boys $(n=13)$, and the children were between 18 and 24 years old $(M=20.65)$. Although most children in our sample were born after the genocide, 11 of the included children were born in the two years before the 1994 events took place, and at the time, thus, were 1 or 2 years old.

\section{Procedure}

A team of five trained Rwandan researchers conducted indepth, semi-structured interviews with mothers who had lived through the genocide and with their adolescent children. Mothers were interviewed twice. The first interview focused on the household characteristics and living conditions and was, furthermore, used to list the three most negative and most positive events experienced over the life course of the household. The second interview explored the way the mother experienced and dealt with negative events, including the genocide. Furthermore, the second interview also focused on family relations, particularly with the child identified to be interviewed. The interview with the child explored how he or she experienced the household, the relationship with the mother and the available sources of psycho-social or socio-economical support for the family or the household (cf. Berckmoes \& Reis, 2016). All interviews were conducted in Kinyarwanda and recorded. Afterwards, they were verbally transcribed and translated by the field researchers (first interview) and by a qualified Kinyarwanda-speaking English translator (second and third interviews).

\section{Data analysis}

The interviews were thematically analysed by the first and second authors using Atlas.ti software (Muhr, Thomas. (2017). User's Manual for ATLAS.ti 8.0, ATLAS.ti Scientific Software Development GmbH, Berlin, Germany) to develop a coherent coding scheme. This scheme encom-

\begin{tabular}{lc}
\hline Table 1: Characteristics of mothers $(\mathbf{N = 4 1 )}$ & \\
\hline Highest education (\%) & \\
Primary school & $41 \%$ \\
Secondary school & $20 \%$ \\
None & $24 \%$ \\
Unknown & $15 \%$ \\
Living area (\%) & \\
Urban & $1 \%$ \\
Rural & $99 \%$ \\
Geographic living location (\%) & \\
North & $21 \%$ \\
South & $22 \%$ \\
East & $37 \%$ \\
West & $20 \%$ \\
Religion (\%) & \\
Muslim & $5 \%$ \\
Christian & $95 \%$ \\
Social category, not mutually exclusive (\%) & \\
Genocide survivor & $46 \%$ \\
Mixed marriage & $12 \%$ \\
Ex-prisoner & $5 \%$ \\
(Ex-)prisoner's wife & $34 \%$ \\
Paid reparations & $15 \%$ \\
Widow/separated & $36 \%$ \\
\hline
\end{tabular}

\begin{tabular}{lc}
\hline Table 2: Characteristics of adolescent children $(\boldsymbol{N}=\mathbf{4 1})$ \\
\hline Gender (\%) \\
Girls \\
Boys & $68 \%$ \\
Highest education (\%) & $32 \%$ \\
Primary school & \\
Secondary school & $14 \%$ \\
University & $76 \%$ \\
None & $5 \%$ \\
Unknown & $0 \%$ \\
Year of birth (\%) & $5 \%$ \\
1998 & \\
1997 & $27 \%$ \\
1996 & $5 \%$ \\
1995 & $22 \%$ \\
1994 & $7 \%$ \\
1993 & $12 \%$ \\
1992 & $14 \%$ \\
\hline
\end{tabular}


passed both the themes that, based on the literature, had been identified in the research design phase (e.g. family relationships, support in general and parenting), and new themes that were identified inductively (e.g. communicating the past, the role of commemoration period and economic initiatives in the community).

\section{Ethics}

Permission for this research project was granted by the Rwandan Ministry of Health, and ethical approval was obtained through the Rwanda National Ethics Committee (No. 552/RNEC/2016). Before the start of each interview, participants were informed about the research objectives and process, both verbally and through an 'informed consent' form. Furthermore, informants were explained that they could refrain from answering specific questions or withdraw at any moment. Informed consent was obtained from both mothers and children. The respondents were explained that the information obtained would be used for research purposes only and that reporting would not contain information that could be traced back to individuals. We also notified participants that we would transcribe, anonymize and securely save the interviews and audio files. The 'waiting list' procedure ensured that respondents had access to trained community socio-therapists, if necessary.

\section{RESULTS}

We identified both the direct and indirect pathways of the intergenerational transmission of the legacies of the genocide within families [Figure 1]. The direct pathways concern the ways in which parents' experiences with the genocide (i.e. the acts of violence) and its aftermath are reflected upon, reconstructed and explicitly communicated, or not, to the second generation. The indirect pathways are the ways in which the genocide and its aftermath currently still affect the second generation's living circumstances, and through that, the child and its development

\section{Direct pathways of intergenerational transmission}

We identified a large variety of ways in which mothers communicate with their children about the genocide, both in terms of how and what is being communicated towards children. The patterns of communication consisted of either explicit, verbal communication or the absence of verbal communication between parents and their children, which in the literature is often referred to as 'silence/ing' (e.g. Weingarten, 2004). An example of explicit, verbal communication is shown in the narrative of a young man (aged 18) who described what his mother shared about her experiences during the genocide:

'It means that during that period [ . . . ] we used to sit down, and she would tell us stories [about the past]; in fact, when you often talk to your parents, they tell you a lot of things. So she would tell us those who killed her parents; she would tell us their living conditions before, in those hard moments'. (Household \#19, son, aged 18, mother is genocide survivor)

Motivations for verbalising or silencing the experiences of the past varied. Most commonly, mothers expressed hesitance to share the stories about the genocide and its aftermath with their children. They appeared concerned about the effects these stories may have on keeping the past alive, wanted to reassure their children by not showing their emotional struggles or felt that it served no purpose to recount these past stories. Their narratives included remarks such as 'letting go of the past', 'bygone is bygone', 'it is history' or 'I have transcended it'. Some mothers felt that children would not understand and emphasised the need to move on, albeit out of necessity:

'I can't see any major effects because what some people don't understand, during the genocide for instance, they were not there. I mean these young ones. But they have reconciled themselves with their father's death, we all live with it. We share the responsibilities that he should be fulfilling and no one gets overtired. Besides, there are things against which you cannot do anything. That's the reason why we have to accept it.' (Household \#13, mother, aged 59, genocide survivor, widow)

Although not observed often in our interviews, there were mothers who worried that their children, should they hear the stories, would come to hate others or seek revenge:

Interviewer: ' [ . . ], do you think that current or past conflicts are likely to affect future generations from the families that experienced them?' indirect pathways of transmission Family composition Family functioning +/ Family socio-economic situation Community relationships

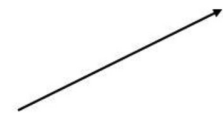

G1

\begin{tabular}{|l|}
\hline genocide \\
\hline \\
Violence \\
Death \\
Looting \\
Fleeing
\end{tabular}

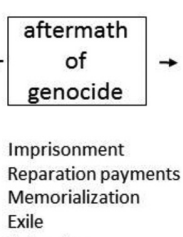

Exile Relocation

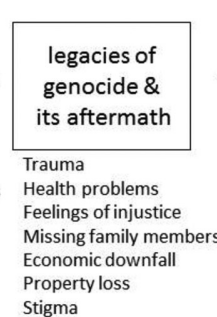

direct pathways of transmission

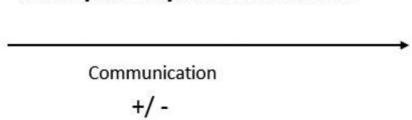

+ -

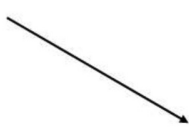

G2

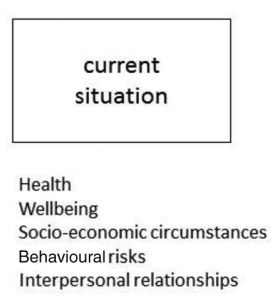

Figure 1: Pathways of transmission 
Eichelsheim et al.: Intergenerational legacies of genocide

Mother: 'This must happen; for example, when a child asks you: What happened to your family? Who killed them? Right? In the future, they will say: it is these ones who killed our grandfathers, our aunts, our cousins. They will say: long ago Hutus killed Tutsis, they were in power of such and such . . . ; let us also kill them. Our grandfathers also were in power of such and such ... On one side, there will be children who will not know the families of their parents. You see, some children's fathers are in prison, right? They also say: I wish someone could show me who had my parents jailed. Right? They would say: we would also kill them.' (Household \#10, mother, aged 40, genocide survivor, mixed marriage)

Remembering the genocide is engrained in everyday life in Rwandan society (Links, 2014). For mothers and children, issues regarding communication or silence about the genocide appeared to become most explicit during the genocide commemoration period, which takes place each year in the month of April. Especially during this period, from the interviews we learned that some children were very eager to learn more about it and - especially during the commemoration period - would not stop asking questions about what happened during the genocide. In this period, otherwise largely private suffering becomes more explicit and almost an unavoidable part of the public domain. Still, not all sufferings emanating from the genocide and its aftermath are communicated openly. Some might be hesitant to vocalise and share publicly feelings such as mistrust or hatred, because such public expressions can be considered sensitive and dangerous (Divisionism Law, 2001; Genocide Ideology Law, 2008).

\section{Indirect pathways of intergenerational transmission}

In Rwanda, one cannot go past the fact that, in many families, children grow up in single-parent households, face difficult economic circumstances and have limited access to institutional support, education and (mental) health care (also refer Rieder \& Elbert, 2013). These circumstances may be related to the genocide and its aftermath. The legacies of the genocide and its aftermath may, thus, also be transmitted through the adverse circumstances in which the child grows up. We identified a number of such indirect pathways of intergenerational transmission, including disturbed family structures such as missing or unavailable family members (i.e. family composition), compromised family functioning, which sometimes became manifest in marital conflict or domestic violence, inadequate caregiving (i.e. parenting), poverty (i.e. difficult socio-economic situation) and problematic community relationships. Of course, these pathways are likely to be interrelated; due to the absence or unavailability of family members, specific family tasks are no longer fulfilled, or parents may have limited possibilities to provide for basic needs of their children, which subsequently means that they are less available because they are occupied with procuring a livelihood. Moreover, many mothers in our sample seemed to have suffered from physical or mental illness. In this section, we describe poverty as one of these indirect pathways of transmission. Throughout our interviews with mothers and children, in all provinces, poverty, which was almost always perceived to be at least partially related to the genocide and its aftermath, was mentioned as a strong concern.

In most interviewed households, both mothers and adolescent children expressed fears about economic 'falling' and expressed the wish to 'improve conditions'. Many families included in our sample had experienced economic downfall after the genocide. Some families had lost land and cattle through looting during the genocide. Some mentioned conflicts over land ownership as people returned to Rwanda after years of exile. Others were affected by postgenocide transitional justice mechanisms such as (substantial) payments of reparations, which - as they are seen as a family responsibility - had heavy impacts on the family's economic resources:

'I was harmed by the death of relatives and I was harmed by the effect of paying damages to the survivors who accused my husband of taking materials during Gacaca period.' (Household \#27, mother, aged 47, widow)

Furthermore, most of the included households had lost family members who could have participated in the economy of the household. In these households, mothers had become primarily responsible for the household economy, often with little resources for help in the extended family. As such, being a mother was by many experienced as a heavy burden. Mothers also expressed worries about not being able to help their children prepare for independent householding. Some mothers expressed their feelings of frustration, anger and injustice about the events that - as they perceived it - had caused the poor living conditions and limited opportunities to improve their household conditions:

'There is no hope. Even getting a meal is a problem. Getting soap is a thorny exercise. To tell you the truth, girl, except when you become patient and courageous, nobody will know that you have all these needs or that you have everything ( . . . ).' (Household \#26, mother, aged 59, genocide survivor, mixed marriage)

It should be noted, however, that despite their losses and having to face new challenges constantly, we also oftentimes found the indicators of resilience, courage and hope to improve the family's conditions and the conditions for the next generation:

'The events I experienced resulted in my being overwhelmed by too much work in the household due to poverty following the genocide. Facing problems means not to be idle or not to be discouraged and stop working. I work although there are failures; I'm not discouraged by the failures. I work hard in the field although the moles eat the crops, but I don't give up. I keep facing the problems so that I can lift myself out of poverty. I cannot stop breeding animals fearing that they may be stolen. I try to lift myself out of poverty.' (Household \#41, mother, aged 52, genocide survivor, widow)

Although in the interviews with mothers and children oftentimes great resilience as well as aspiration for a better future was shown, experiences with economic hardship and 
Eichelsheim et al.: Intergenerational legacies of genocide

downfall were also shared. These experiences manifested themselves in the first place in the lack of fulfillment of basis needs. For instance, several children were prevented from going to school, because mothers could not pay for uniforms, school meals or other school material:

'It's true, compensation took place, of course I paid with difficult [y], ( . . . ) But I say: the money I paid could have enabled a child to go to school, but it happened like that. I accept it because there is no option. Yes.' (Household \#12, mother, aged 40, prisoner's wife)

Although it is quite common in many African societies for children to participate in the running of the household (e.g. Levine et al., 1994; Levine \& New, 2008), among the sampled households, burdens on the children in the household appeared to be heavy. Children or adolescents do not always know about the cause of the economic difficulties in their families, or do not (completely) understand:

Child: 'Because they [i.e. parents] had cut trees, and were requested to refund them. That is all I know about the case [i.e. obligation to pay reparations].'

Interviewer: 'Was your mother the only one to suffer from that problem?'

Child: 'Yeah, she was the most to suffer because she did not cut the trees herself.'

Interviewer: 'Yes! Oh . . . Does it have consequences for the relationship with her?'

Child: 'Of course, because she has paid money, the whole household has suffered.' (Household \#6, daughter, aged 20 , mother is genocide survivor)

\section{Pathways of intergenerational transmission and institutional support}

In our sample, there were many families that had access to at least some kind of institutional support, whether it was socio-economical, medical or psychosocial. The sources of support that were mentioned could be governmental (e.g. the one cow per poor family programme), non-governmental (i.e. organised by non-governmental organizations) or, oftentimes, also organised through religious institutions. When asking about the households' most important sources of support, many ex-participants of the sociotherapy programme indicated that - among other received forms of support - the programme had been very important to them in their lives. All respondents oftentimes mentioned support from churches or priests, healthcare centres or local community initiatives such as tontines (i.e. communal investments), like this mother who described joining trauma education programmes organised by churches and priests, and a support group for widows:

'One day, the priest made ... they announced that the priest wanted to meet with the widows, that they should get together. ( . . . ) Then we went on Tuesday. We met people from Muhanga and people from this neighbourhood. Then we formed associations and contributed small amounts of money, we prayed and went home. (. . . )
The programme initiated by the parish taught us about trauma and trauma healing. Since I started attending the programme, Ifeel a bit relieved. It was a good thing because they even gave us a booklet about it. When I'm not feeling well, I take it and ask somebody to read for me, and I feel better. It was a very good thing. Besides, I'm no longer feeling lonely. I've joined a widow's association. I'm little by little living a normal life, trauma-related problems are no longer frequent ( . . . ).' (Household \#18, aged 55, widow)

With these types of institutional support, both the direct and indirect pathways of transmission are being addressed, because the offered support improves the current life circumstances of the mother, and, therewith, also the living conditions of the children. Moreover, the aforementioned example clearly illustrates that the often-communal character of psychosocial support groups also facilitates socioeconomic initiatives among its participants.

In the current study which was conducted in close cooperation with community-based sociotherapy in Rwanda (CBS), we also wanted to explore the role that sociotherapy plays in the processes of the intergenerational transmission of the legacies of the genocide. With regard to the direct pathways of intergenerational transmission, some respondents mentioned that the community-based sociotherapy has stimulated them to share personal stories about their own experiences during the genocide with their children. For instance, this respondent describes how she finally dared to take her children to a memorial site, which stimulated open discussion with her children about the past experiences of violence:

'But now, Ifeel such behaviour [referring to her emotional absence and feelings of anger and frustration especially during the commemoration period] is weakening, because of the community sociotherapy programme I have joined. This year particularly, I dared taking my children to the memorial site. When I uttered my testimony on the dark moments with genocide, the children came to realize that my behaviour is seriously hindered by the genocide and they encourage me. At the moment, such an event [referring to going to the memorial site] no longer threatens me to the extent of disturbing my children' (Household \#23, mother, aged 47, genocide survivor, mixed marriage)

With regard to the indirect pathways of intergenerational transmission, we noticed that in community-based sociotherapy sessions, issues related to the (mental) health of caregivers, family functioning (i.e. marital and parent-child relationships), as well as issues related to stigma in the community were oftentimes addressed. Mothers we spoke to mentioned that their sociotherapy group's focus was on 'healing', its group-based promotion of forgiveness and the importance of 'moving on'. They noted that the intervention had helped them living with the suffering they had experienced and feeling human again. Some felt that they could 'relativise' and, in a way, 'normalise' their suffering, because they noticed that other people were worse off than they were. Other mothers reported that sociotherapy helped them to stop avoiding places or people that reminded them of events that happened during the genocide, or helped them to come out of isolation from the community. 
Eichelsheim et al.: Intergenerational legacies of genocide

'They [the sociotherapists] said: "We can now start talking about this issue, then after fifteen days, we shall start some healing programme with you". From the discussion we had that day, Ifelt satisfied. I was taught to visit the persons we were having problems with: "Please, feelfree with them. You should no longer be on bad terms each other, greet them as you pass. Talk to them". That day we had a good discussion.' (Household \#28, mother, aged 45, widow, ex-participant CBS)

Not only sociotherapy, but also the other forms of institutional support, appear not to explicitly engage within the direct pathways of intergenerational transmission such as poverty and compromised family structures due to the loss of family members, at least, not targeting them explicitly as the pathways of transmission to the next generation. Still, we came across various examples in the interviews and our observations in the field that suggest that sociotherapy may bring benefits in this respect, because it can stimulate groupbased socio-economic initiatives. In terms of the indirect pathways of intergenerational transmission, such initiatives can be said to - to some extent - address the loss of family members and its effects on the socio-economic situation of a household, and especially address poverty, the fear for economic downfall and the need or wish to improve family and individual living conditions. The woman whom we quoted previously, indeed, continues her story as follows:

'After the discussion, we were told: "We are going to start collecting some contribution. After one year, we shall break the box and see the amount of money inside, and each of us will be able to buy something from the contributions. So, you can give your ideas, on the contribution". I said: "My idea is that I don't have enough means to pay for my children's school fees; one is going to the secondary school; another has just completed senior three". Then he[the sociotherapist] told us, because we were trained by [sociotherapists]: "Our contribution for you will be to collect some money in a box, and at the end of the year, you will have some money to buy pens for your children. That will also be the same for the rest of the group". [ . . . ] To me, that is the importance of the sociotherapy programme up to now.' (Household \#28, mother, aged 45, widow, ex-participant CBS)

Similarly, due to its community-based character, we found that participation in sociotherapy groups enabled socioeconomic initiatives directed at the neighbourhood:

'As I told you, my husband is a member of the communitybased sociotherapy group and that his fellow members lend us a hand during the farming season, which we appreciate a lot. For this reason, this support can't [negatively] affect our relationship with others in this neighbourhood. Instead, it is a good opportunity for us to discuss about how we can develop our neighbourhood. The most important support is to get constructive ideas, which lead to the development of the neighbourhood.' (Household \#7, mother, aged 51, genocide survivor, husband is ex-participant CBS)

\section{Concluding Remarks}

In Rwanda, the genocide against the Tutsi and its legacies are still present in people's memories and through memorial sites and annual commemoration events. The tragic past very much shapes the present and, via the next generations, may also affect the future despite the omnipresent aspiration of Rwandans to build a better future. Our first aim was to investigate how the legacies of genocide and its aftermath are transmitted within families to future generations. We focused specifically on relationships and interactions between mothers and their children. Our second aim was to explore how community-based sociotherapy, among other sources of institutional support may play a constructive role in the processes of intergenerational transmission in Rwanda.

Our findings revealed that the legacies of the 1994 genocide and its aftermath are transmitted to the second generation within families through direct and indirect pathways, which are interrelated and interact in multiple ways. The direct pathways of intergenerational transmission concern the ways in which the genocide and its aftermath are reflected upon, reconstructed and explicitly communicated, or not communicated, to the second generation. The indirect pathways of intergenerational transmission are the ways in which the genocide affects the second generation's socio-ecological environment, and, through that, may affect the child and its development. In this study, we specifically focused on communication (or a lack thereof) as the direct pathway of intergenerational transmission, as well as economic difficulties as a salient example of an indirect pathway.

Direct pathways involve the communication with or towards children about the negative events of the past. A lack of communication with children or the 'silencing' of past events was also observed. Silencing may be a deliberately chosen strategy, for example, for mothers not to show their struggle (cf. Weingarten, 2004). Silence could, however, also function as a way to 'let go of the past' and was also described as a way to be able to live peacefully together and to focus on the future. Sociotherapy - similar to many other forms of psycho-social support - facilitates direct, verbal communication about difficulties with regard to daily life struggles, which may be related to the genocide (e.g. living together with perpetrators or economic downfall). Some of our interviewees noted that directly confronting the past and sharing their traumatic experiences enabled them to 'relativise' or 'normalise' their suffering. They saw that other people also suffer and may even be worse off than they were themselves. With regard to the intergenerational family bonds and relationships, open communication about the genocide and its legacies can lead to children's increased understanding of their current struggles. At the same time, we know from the literature that it can also generate frustration, open old wounds or lead to traumatisation (e.g. Roth et al., 2014).

With regard to the indirect pathways of intergenerational transmission, we described poverty as one of the most salient examples of an indirect intergenerational pathway. Although we found many examples of resilience - the strength and courage to improve conditions for the family, both among mothers and their children, the perceived economic downfall was frequently referred to by both mothers and children as hampering them in their daily 
Eichelsheim et al.: Intergenerational legacies of genocide

lives and obstructing opportunities for the future. For children, the consequences of the economic hardship and downfall manifested themselves in the first place in the lack of fulfilment of basic needs, their inability to attend school and, therewith, secure their future. They reported feeling obliged to alleviate family poverty by contributing to household activities and generating sources of income, which is also found in other studies dealing with children growing up in poverty (e.g. Ananga, 2011; Jukes, Jere, \& Pridmore, 2014). Although not directly aimed to alleviate poverty, sociotherapy and also other community-based interventions try to build the capacity of people to take more (joint) initiative to improve living conditions. It thus appears that by bringing people together, enabling them to share their experiences and opening up to each other, these interventions may stimulate group-based cooperation and socio-economic initiatives among its participants. This in turn enables people to improve their living conditions and, therewith, prevent ongoing negative effects on the socioecological environment in which their children grow up. In other words, the constructive role the various forms of institutional support plays in the lives of these individuals show the potential to break the negative patterns of transmission over the course of generations (also refer Ingabire et al., 2017).

\section{Limitations and strengths}

As with any research, there were some limitations in the current study and its design. First, all respondents had been or were about to be enrolled in a therapeutic intervention, which may indicate that the sample consists of vulnerable groups of individuals and families. The sample is relatively small, and we used in-depth qualitative interviews with mothers and children to address how rather than to what extent the legacies of the genocide are being transmitted across generations within the context of the family. We wish to underline that we do not suggest that this sample of households is representative for all Rwandan families. Second, although we included deliberately two groups of mothers - enrolled or not yet enrolled in a community-based sociotherapy intervention - the current study does not pretend to be an evaluation of the intervention. The rich qualitative data were used to explore how the intervention among other forms of available support did play a role in the identified pathways of intergenerational transmission.

Besides these limitations, one of the most important strengths of the current study is the use of the rich qualitative data that has been gathered through interviewing both mothers and one child of each mother. The focus on multiple mechanisms through which the legacies of the genocide may be passed on to next generations, as well as exploring the potential role of institutional support to prevent the negative outcomes of intergenerational transmission, can also be considered an important strength of the current study.

\section{Implications}

To target the potential negative or harmful outcomes of the intergenerational transmission of legacies of the genocide and its aftermath more directly, in their further implementation, the CBSP and other organisations working with families in post-conflict settings might want to consider focusing explicitly on these and other pathways of intergenerational transmission by:

(1) Encouraging their participants to address parenting, family relations and family interactions explicitly to help each other to secure a safe environment for their children to grow up in.

(2) Encouraging group participants to fulfil the roles of absent family members by taking care of each other and each other's children, thereby fulfilling roles generally ascribed to family members. By extending the focus of the interventions to the group members' children, sociotherapy or other communal support interventions may aid in preventing the negative consequences of the genocide and its aftermath for next generations.

(3) Stimulating and supporting participants to develop economic cooperation with fellow participants and within the community to reduce poverty.

(4) Exploring partnerships with other organisations who can contribute to positive outcomes for next generations.

To conclude, by purposefully addressing the direct and indirect pathways of intergenerational transmission within their existing programmes and their oftentimes community-based structure, the CBSP and other organisations working in post-conflict settings may be even better equipped to improve conditions for future generations.

\section{Declaration of respondent consent}

The authors certify that they have obtained informed consent. For those who were able to read the form, it was read aloud to them and verbal consent was obtained. The respondent(s) has/have given his/her/their consent for his/her/their information to be reported in the journal. The respondents understand that their names and initials will not be published and due efforts will be made to conceal their identity.

\section{Acknowledgements}

The authors thank all cooperating partners, interviewers and, especially, the respondents for their willingness to share their time and impressive stories with us. We thank the translator for translating the interviews from Kinyarwanda to English.

\section{Financial support and sponsorship}

The project was funded by NWO-WOTRO, the Applied Research Fund of the Security \& Rule of Law programme (grant number W 08.400.124/779).

\section{Conflicts of interest}

There are no conflicts of interest.

\section{REFERENCES}

Ananga, D. (2011). Typology of school dropout: The dimensions and dynamics of dropout in Ghana. International Journal of Educational Development, 31(4), 374-381. doi: 10.1016/j.ijedudev.2011.01.006 
Eichelsheim et al.: Intergenerational legacies of genocide

Berckmoes, L. H., De Jong, J. T. V. M., \& Reis, R. (2016). Intergenerational transmission of violence and resilience in conflict-affected Burundi: A qualitative study of why some children thrive despite duress. Global Mental Health, e26. doi: 10.1017/gmh.2017.23

Betancourt, T. S., \& Williams, T. (2008). Building an evidence base on mental health interventions for children affected by armed conflict. Intervention, 6(1), 39-56. doi: 10.1097/WTF.0b013e3282f761ff

Betancourt, T. S., McBain, R. K., Newnham, E. A., \& Brennan, R. T. (2015). The intergenerational impact of war: longitudinal relationships between caregiver and child mental health in postconflict Sierra Leone. Journal of Child Psychology and Psychiatry, 56(10), 11011107. doi: $10.1111 /$ jcpp. 12389

Buckley-Zistel, S. (2006). Remembering to forget: Chosen amnesia as a strategy for local coexistence in post-genocide Rwanda. Africa, 76 (2), 131-150. doi: 10.3366/afr.2006.76.2.131

Clark, P., \& Kaufman, Z. D. (Eds.). (2008). After genocide, transitional justice, post-conflict reconstruction and reconciliation in Rwanda and beyond. United Kingdom: Hurts Publishers.

Dekker, C. (2016). Terugvinden van waardigheid: Community-based sociotherapy in Rwanda, Oost Congo en Liberia (Dissertation). Amsterdam: VU University Press.

Divisionism Law. (2001). Law No. 47/2001 of 2001 on prevention, suppression and punishment of the crime of discrimination and sectarianism. Retrieved from http://www.refworld.org/docid/ $4 \mathrm{ac} 5 \mathrm{c} 4302 . \mathrm{html}$

Genocide Ideology Law. (2008). Law No. 18/2008 of 2008 relating to the punishment of the crime of genocide ideology. Retrieved from http:// www.refworld.org/docid/4acc9a4e2.html

Gewirtz, A., Forgatch, M., \& Wieling, E. (2008). Parenting practices as potential mechanisms for child adjustment following mass trauma. Journal of Marital and Family Therapy, 34(2), 177-192. doi: 10.1111/j.1752-0606.2008.00063.x

Ingabire, C. M., Kagoyire, G., Karangwa, D., Ingabire, N., Habarugira, N., Jansen, A., \& Richters, A. (2017). Trauma informed restorative justice through community based sociotherapy in Rwanda. Intervention, 15(3), 241-253. doi: 10.1097/WTF.0000000000000163

Jukes, M., Jere, C., \& Pridmore, P. (2014). Evaluating the provision of flexible learning for children at risk of primary school dropout in Malawi. International Journal of Educational Development, 39, 191202. doi: 10.1016/j.ijedudev.2014.07.006

Kim, J. (2009). Type-specific intergenerational transmission of neglectful and physically abusive parenting behaviors among young parents. Children and Youth Services Review, 31(7), 761-767. doi: 10.1016/j. childyouth.2009.02.002

Levine, R. A., Levine, S., Dixon, S., Richman, A., Keefer, C. H., \& Leiderman, P. H. (1994). Child care and culture: Lessons from Africa. Cambridge: Cambridge University Press.

Levine, R. A., \& New, R. S. (Eds.). (2008). Anthropology and child development: A cross-cultural reader. Oxford: Wiley-Blackwell.

Links, P. (2014). Preserving history in Rwanda. Retrieved from http:// www.niod.nl/en/lecture-petra-links-preserving-history-rwanda
Neugebauer, R., Fisher, P. W., Turner, J. B., Yamabe, S., Sarsfield, J. A., \& Stehling-Ariza, T. (2009). Post-traumatic stress reactions among Rwandan children and adolescents in the early aftermath of genocide. International Journal of Epidemiology, 38(4), 1033-1045.

Rees, S., Thorpe, R., Tol, W., Fonseca, M., \& Silove, D. (2015). Testing a cycle of family violence model in conflict-affected, low-income countries: A qualitative study from Timor-Leste. Social Science \& Medicine, 130, 284-291. doi: 10.1016/j.socscimed.2015.02.013

Richters, A., \& Sarabwe, E. (2014). Everyday partner violence in Rwanda: The contribution of community-based sociotherapy to peaceful family life: Original contribution. African Safety Promotion, 12(1), 18-34.

Rieder, H., \& Elbert, T. (2013). Rwanda - Lasting imprints of a genocide: Trauma, mental health and psychosocial conditions in survivors, former prisoners and their children. Conflict and Health, 7(1), 6 . doi: 10.1186/1752-1505-7-6

Roth, M., Neuner, F., \& Elbert, T. (2014). Transgenerational consequences of PTSD: Risk factors for the mental health of children whose mothers have been exposed to the Rwandan genocide. International Journal of Mental Health Systems, 8(1), 1-12. doi: 10.1186/1752-4458-8-12

Rwanda, Ministry of Local Government. (2002). The counting of the genocide victims: Final report. Kigali: Republic of Rwanda.

Rutayisire, T., \& Richters, A. (2014). Everyday suffering outside prison walls: A legacy of community justice in post-genocide Rwanda. Social Science \& Medicine, 120, 413-420. doi: 10.1016/j. socscimed.2014.06.009

Saile, R., Ertl, V., Neuner, F., \& Catani, C. (2014). Does war contribute to family violence against children? Findings from a two-generational multi-informant study in Northern Uganda. Child Abuse \& Neglect, 38, 135-146. doi: 10.1016/j.chiabu.2013.10.007

Sarabwe, E., Richters, A., \& Vysma, M. (2017). Marital conflict in the aftermath of genocide in Rwanda. An explorative study in the context of community-based sociotherapy. Intervention. doi: 10.1097/ WTF.0000000000000147

Schindler, K. (2010). Who does what in a household after genocide? Evidence from Rwanda (Discussion Paper No. 1072). DIW Berlin, German Institute for Economic Research.

Tertsakian, C. (2004). Le Chateau. The lives of prisoners in Rwanda. UK Arves Books.

Thornberry, T. P., Knight, K. E., \& Lovegrove, P. J. (2012). Does maltreatment beget maltreatment? A systematic review of the intergenerational literature. Trauma, Violence, \& Abuse, 13(3), 135-152. doi: $10.1177 / 1524838012447697$

Umubyeyi, A., Mogren, I., Ntaganira, J., \& Krantz, G. (2014). Women are considerably more exposed to intimate partner violence than men in Rwanda: Results from a population-based, cross-sectional study. BMC Women's Health, 14, 99-110. doi: 10.1186/s12888-014-0315-7

Weingarten, K. (2004). Witnessing the effects of political violence in families: Mechanisms of intergenerational transmission and clinical interventions. Journal of Marital and Family Therapy, 30(1), 45-59. doi: 10.1111/j.1752-0606.2004.tb01221.x 